\title{
The 25th anniversary of Journal of Material Science: Materials in Electronics
}

\author{
Arthur Willoughby ${ }^{1}$
}

Published online: 3 June 2015

(c) Springer Science+Business Media New York 2015

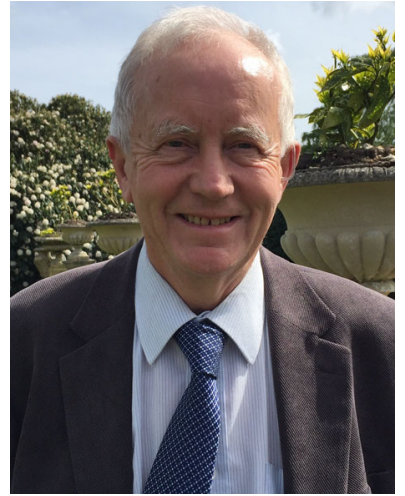

Editor-in-Chief

Professor Arthur Willoughby

Photo by Charles Glaser

The first issue of J.Mater.Sci: Materials in Electronics was published in 1990, and so this year represents completion of the first 25 years in the journal's history. As the founding Editor, and Editor-in-Chief for the all of that time, it is a great pleasure to write an Editorial to mark the occasion.

As a companion journal to the main Journal of Materials Science, the initiative to launch this journal, together with J.Mater.Sci: Materials in Medicine, was very much thanks to the then Editor of Journal of Materials Science, Professor Bill Bonfield, and the publishing Editor of Chapman and Hall (who published these journals then), Michael Dunn. Their foresight in recognising the strength of these disciplines, and the need to cover them with

Arthur Willoughby

A.F.Willoughby@soton.ac.uk

1 University of Southampton, Southampton, UK specialist journals, cannot be emphasised too strongly, and the subsequent success of this journal is witness to their initiative. In the first few years, both Bill Bonfield and Michael Dunn helped to ensure a strong launch to make it successful, and both are recognised here for their invaluable contribution to the journal.

As a new journal in this field, to join the respected and established TMS/IEEE Journal of Electronic Materials, whose Editor, Professor Ted Harman, was always extremely encouraging to me personally, this journal was able to embrace a wide range of aspects of materials in electronics, which has been recognised more recently on the mast-head to cover Optoelectronic Materials and Photon$i c s$ in addition to the more traditional areas. The first issue contained papers on solar cells, electroceramics, infra-red detector materials, resistors, high-Tc superconductors, optical fibres, magnetic materials, glasses, thin films and phosphors, in only 12 papers! Likewise these first papers included authors from the UK, USA, Japan, France, Italy, Australia, India and Egypt.

This Special Issue starts with a series of specially submitted reviews and regular papers, representing important fields covered by the journal over those 25 years, bringing them up to date with the latest progress. Fields covered include some of those appearing in the first issue 25 years ago, such as solar cell materials and magnetic materials, together with subjects covered in past featured issues such as lead-free solders (January 2012), but also reflects very recent developments such as graphene, flexible electronics, energy storage, lead-free piezoelectrics, organic semiconductors, solid state lighting, magnonic and spintronic devices, and electrically conducting adhesives.

All reviews which are a regular feature of our journal, have been edited by my distinguished colleague, Professor Safa Kasap from the University of Saskatchewan, Canada, 
who is Deputy Editor of the journal, as well as our Reviews Editor, and has made a major contribution to this issue. I here record my sincere appreciation of Professor Kasap's tremendous contribution to the journal, since he was appointed in 2001 as Reviews Editor, and in 2006 as Deputy Editor.

The growth in the number of papers submitted to the journal has been very fast, particularly in recent years, and we have been fortunate that Springer have introduced online publication and Editorial management, which has been immensely helpful in our task. In the first year of the journal in 1990, four issues were published containing 47 papers and 229 pages; in 2009, 12 issues were published containing 188 papers and 1259 pages, and in 2014 the 12 issues contained 927 papers and 5651 pages. In parallel with this, the Editorial Board has determined to publish papers of only the highest quality, and most significant in impact, with the result that the Impact factor has risen from 0.417 in 1999 to its present level of 1.966 in 2013. In short, in the 4 years from 2010 to 2014 the journal has quadrupled in size, and doubled its Impact Factor!!

To handle this tremendous growth, we have begun to appoint Associate Editors, who are handling regular papers on behalf of the journal, and in the last year we have been delighted to welcome Peter Capper, Patrick McNally, and Maurizio Martino as our first Associate Editors. We intend to make further appointments as the journal grows.

In all of the successive developments of the past 25 years, I pay tribute to the Editorial Board, who have been tremendously supportive, together with referees, and authors. I thank successive Publishing Editors of the journal, including Michael Dunn (Chapman and Hall and Thomson), Carl Harris (Kluwer Academic), Greg Franklin (Kluwer and Springer), Alex Greene (Springer), and Charles Glaser (Springer), to whom we owe special thanks for this issue, together with the editorial and production staff of these publishers who have made this all possible. At Southampton University, my grateful thanks go to Gill Rood, my editorial assistant, for her unstinting efficiency and loyalty throughout this long period.

In the first Editorial that I wrote for the launch of the journal, I emphasised the need for a journal to extend the coverage of materials science to incorporate their role in the applications themselves. In my view, this issue illustrates the continuing need for such a coverage in the rapidly growing field of materials in electronics, optoelectronics and photonics. 